\title{
A INFLUÊNCIA DO LÚDICO NO DESENVOLVIMENTO INFANTIL
}

\author{
THE INFLUENCE OF PLAYING IN CHILDREN'S DEVELOPMENT
}

\author{
Paula Duarte Fonseca \\ Claretiano Centro Universitário de Foz do Iguaçu, Foz do Iguaçu, PR, Brasil. E-mail: \\ pauladuartefonseca1@hotmail.com \\ Margarete Pereira da Silva \\ Faculdade Pitágoras - Unopar. E-mail: margareth.maga_12@hotmail.com

\section{Petterson Soares Leite} \\ Claretiano Centro Universitário de Foz do Iguaçu, Foz do Iguaçu, PR, Brasil. E-mail: \\ pettersonsoares99@gmail.com
}

DOI: https://doi.org/10.46550/amormundi.v2i6.123

Recebido em: 18.08.2021

Aceito em: 09.10.2021

\begin{abstract}
Resumo: Por meio do brincar surge a interação entre a espontaneidade e a criatividade com a progressiva aceitação das regras sociais e morais por parte da criança. Entáo é brincando que o indivíduo se humaniza e aprende a conciliar de forma afetiva a afirmação de si mesmo à criação de vínculos afetivos duradouros. Diante disso, este artigo trata da influência do lúdico no desenvolvimento infantil e apresenta resultados de uma pesquisa qualitativa, cujo objetivo tratou de discutir sobre a importância das práticas lúdicas no processo de desenvolvimento da criança, visando à construção do conhecimento e aprendizagem por meio de jogos e brincadeiras. Realizou-se uma revisão bibliográfica no qual apresenta-se as contribuiçóes que o jogar e brincar proporcionam para o processo de construção do conhecimento. Portanto, através deste artigo, é possível afirmar que, enquanto recurso didático-pedagógico, o lúdico permite novas maneiras de ensinar, associado a aspectos que podem tornar o ensino mais atrativo, interessante e contribuir com uma educação de maior qualidade, capaz de atender aos interesses essenciais à criança.
\end{abstract}

Palavras-chave: Lúdico. Jogos e Brincadeiras. Aprendizagem. Desenvolvimento.

\begin{abstract}
Through play, the interaction between spontaneity and creativity emerges, with the child's progressive acceptance of social and moral rules. So, it is by playing that the individual becomes human and learns to affectively reconcile self-affirmation with the creation of lasting affective bonds. Therefore, this article deals with the influence of play on child development and presents the results of a qualitative research, whose objective was to discuss the importance of play practices in the child development process, aiming at the construction of knowledge and learning through games and games. A bibliographical review was carried out in w, hich the contributions that playing and playing provide to the knowledge construction process are presented. Therefore, through this article, it is possible to state that, as a didactic-pedagogical resource, the ludic allows new ways of teaching, associated with aspects that can make teaching more attractive, interesting and contribute to higher quality education, capable of meeting interests essential to the child.
\end{abstract}

Keywords: Playful. Games and Pranks. Learning. Development. 


\section{Introduçáo}

ato brincar é uma importante ferramenta que contribui para o desenvolvimento
de uma série de habilidades na criança, permitindo que ela aprenda e compreenda o mundo do qual faz parte, bem como a cultura e as regras do seu meio social. A promoçáo de atividades que envolvem jogos e brincadeiras oportunizam um ambiente para que o aluno expresse seus sentimentos, favorecendo também o desenvolvimento da sua afetividade e a assimilação de novos aprendizados. Em outras palavras, o brincar é elemento fundamental na vida da criança, uma vez que estimula a inteligência, a imaginação e a criatividade.

É no brincar que surge a interação entre a espontaneidade e a criatividade, com progressiva aceitação das regras sociais e morais por parte da criança. É brincando que o indivíduo se humaniza e aprende a conciliar de forma afetiva a afirmaçáo de si mesmo à criaçáo de vínculos afetivos duradouros. Na brincadeira a criança representa, cria, usa o faz de conta para entender a realidade que a cerca e vive o momento. É uma atividade espontânea da criança que carrega consigo estímulos relacionados à fantasia e à imaginaçáo, e que despertam o gosto pela vida, oportunizando o desenvolvimento afetivo, cognitivo, motor, social e moral.

O lúdico atua no processo de desenvolvimento e aprendizado da criança. Desse modo, considerando que a ludicidade é uma necessidade do indivíduo, e uma ferramenta indispensável no aprendizado e desenvolvimento infantil, o brincar possibilita à criança a construção e a compreensão de conhecimentos. Por isso, o desenvolvimento que o universo lúdico viabiliza, agrega elementos aos fatores sociais e culturais, favorecendo a saúde física e mental, auxiliando no processo de socialização e proporcionando melhores condiçôes de comunicação e conhecimento.

Sendo assim, este artigo trata da influência do lúdico no desenvolvimento infantil e apresenta resultados de uma pesquisa qualitativa, cujo objetivo tratou de discutir sobre a importância das práticas lúdicas no processo de ensino-aprendizagem da criança, visando à construção do conhecimento e ampliação das habilidades por meio de jogos e brincadeiras. Para viabilizar este estudo, realizou-se um uma revisão bibliográfica no qual apresenta-se as principais contribuiçôes proporcionadas pelas práticas lúdicas ao longo da trajetória educacional do indivíduo.

\section{Metodologia}

Considerando as características dos métodos de estudo, o presente artigo é composto pela investigação exploratória a fim de explanar a importância da temática, também de caráter descritivo por observar, registrar, interpretar e discutir a ludicidade como recurso pedagógico no contexto educacional, obviamente, sem interferência nos resultados da pesquisa. Conforme Boccato (2006), esse tipo de pesquisa busca a resoluçáo de um problema por meio de referenciais teóricos publicados, analisando e discutindo as várias contribuiçóes científicas. Também, traz subsídios para o conhecimento sobre o que o assunto pesquisado, como e sob que enfoque e/ou perspectivas tratou-se a temática apresentada na literatura científica.

Segundo Vergara (2007), a pesquisa parte da coleta de informaçóes para um estudo sistematizado desenvolvido com base no levantamento de material publicado em livros, revistas, jornais ou sites. Portanto, o método utilizado nessa proposta correspondeu à pesquisa bibliográfica por conta da fundamentação teórica que se construiu para discutir a temática ao longo do artigo, 
que tem como principal característica "explorar por meio de diferentes autores a essência de um determinado assunto" (LAKATOS, 2007, p. 107).

A análise bibliográfica considera mais a subjetividade do pesquisador, considerando a totalidade das informaçóes, e não dados ou aspectos isolados” (ALYRIO, 2009, p. 11). Desse modo, para viabilizar o levantamento de informaçóes e a elaboraçáo deste artigo, a metodologia adotou a abordagem qualitativa, uma vez que utilizou-se de estudos de casos e artigos científicos sobre a influência da ludicidade no desenvolvimento e aprendizagem infantil. Assim, buscamos analisar minuciosamente todas as informaçóes registradas, interpretando as observaçóes com base nas teorias que sustentaram a revisão bibliográfica da pesquisa.

\section{A importância das práticas lúdicas no processo de ensino-aprendizagem}

O lúdico tem sua origem na palavra em latim "ludus" que significa jogo, mas tal definição sobrepõe o pleno sentido da palavra, uma vez que as implicações proporcionadas pelas atividades lúdicas correspondem ao brincar espontâneo. A expressão lúdico faz referência ao método de ensinar por meio do brincar, podendo ser considerado um recurso utilizado pela criança para se comunicar, se relacionar com o ambiente em que se encontra e para compreender a si mesma e o que está em sua volta. Por isso, tal recurso incentiva ao processo de desenvolvimento infantil. Dessa forma, é possível afirmar que as práticas lúdicas oportunizam os processos de aprendizagem sociais, visto que as crianças aprendem a colaborar umas com as outras, combinando e respeitando as devidas fases.

O desenvolvimento do aspecto lúdico facilita a aprendizagem, suas potencialidades e múltiplas habilidades. Luckesi (2005) comenta que as brincadeiras proporcionam experiências de plenitude, em que o indivíduo se vê inteiramente envolvido. Assim, quando uma atividade lúdica é desenvolvida maior é a possibilidade de que o aluno expresse seus sentimentos, e a partir disso fortaleça seus vínculos afetivos. Além dessa contribuição, a ludicidade permite a vivência de inúmeras práticas corporais, de integração social e cultural entre os participantes.

Sobre isso, Queiroz (2009) ainda destaca que o lúdico é primordial para a criança, uma vez que estimula a inteligência, a imaginação e a criatividade. A ludicidade desenvolvida na rotina escolar proporciona à criança momentos em que ela pode mostrar sua agilidade por meio da competiçáo, refletir sobre o fazer, organizar e desorganizar, construir e reconstruir, e crescer nos aspectos culturais e sociais como parte essencial de uma sociedade. E, como recurso pedagógico, as práticas lúdicas apresentam-se como uma estratégia de ensino essencial para a estabilidade emocional e para o desenvolvimento da personalidade infantil.

Nesse contexto, Moyles (2002) informa que as sensaçóes proporcionadas pelas práticas lúdicas interferem positivamente nas experiências humanas ampliando e diversificando as possibilidades do aluno em ter acesso às produçóes culturais e o estímulo ao desenvolvimento de seus conhecimentos, sua imaginação, criatividade e diversas experiências. Deste modo, por meio das situaçóes promovidas pelo aspecto lúdico, a criança compreende e aprende a respeitar regras, limites e os papéis de cada um na vida real; há a possibilidade de imaginar, criar, agir e interagir, auxiliando-a no entendimento da realidade. De modo geral, o lúdico acontece no cotidiano infantil e é um processo de humanização, no qual o indivíduo aprende a se adequar à brincadeira de forma efetiva, fortalecendo ou criando vínculos afetivos mais duradouros. 
Através das possibilidades inerentes às práticas lúdicas, as crianças ampliam suas capacidades de raciocinar e de julgar, reconhecendo o quanto isto é importante para a atividade em si. $\mathrm{Na}$ dimensão lúdica, as atividades surgem liberadas, livres, gratuitas e sem caráter instrumental. E, por isso, que se configuram como atividade prazerosa que tendem a se aperfeiçoar. Logo, o brincar se torna uma ferramenta importante para o desenvolvimento infantil porque proporcionam inúmeras aprendizagens, dando a chance da criança expandir sua visão e interação com o mundo ao seu redor.

A atividade lúdica é capaz de desencadear sensaçóes de prazer, emoção e adrenalina nos alunos. Isso faz com que eles se sintam incentivados a participar ativamente das propostas, uma vez que a sensação de bem-estar que [a] atividade promove é automaticamente identificada pelo cérebro. Náo bastasse isso, [a ludicidade] nas escolas contribui para o processo de integração social, onde cada criança começa a identificar, desde cedo, o seu papel diante de uma realidade e aprende a conviver com os demais, respeitando os limites e diferenças de cada um de seus colegas de sala (COLÉGIO ERASTO GAERTNER, 2016).

Então, pode-se dizer que a ludicidade na educação busca oportunizar uma aprendizagem ampla e divertida, na qual o estudante consegue aprender com prazer, alegria e entretenimento. Desse modo, as práticas lúdicas na vivência escolar tornam possível desenvolver competências comunicativas, sociais e técnicas, ensinando na prática o indivíduo a lidar com suas próprias necessidades e a de outros, permitindo à este construir a sua autonomia, sua personalidade e ainda desenvolver a linguagem e suas expressões de maneira lógica e organizada.

Portanto, a ludicidade é algo essencial porque promove a troca e a interação. É uma necessidade do indivíduo, que influencia no seu processo de aprendizagem, em suas potencialidades, no seu desenvolvimento cognitivo, social, afetivo, físico e cultural, trabalhando também nos processos de socialização, comunicação, expressão e construção de conhecimento. Ou seja, as práticas lúdicas são de extrema importância para o desenvolvimento infantil, por ser uma necessidade da criança, uma vez que se utiliza dessas atividades para vivenciar a socializaçáo, e apropriação de valores e costumes.

\section{Os jogos e brincadeiras como recurso pedagógico para a aprendizagem infantil}

Os jogos e brincadeiras inseridos na prática pedagógica conferem ao indivíduo a possibilidade de desenvolvimento. Por meio dos jogos e das brincadeiras as crianças estão propensas ao amadurecimento de capacidades de socializaçáo, da utilização e experimentação de regras. Para Piaget (1970), através dos jogos e brincadeiras, a criança constrói conhecimento sobre o mundo físico e social, em todas as fases do desenvolvimento, criando desse modo, um interesse quando postos em prática com finalidade e com eficiência, podendo se tornar a moldura na qual se ampliam todas as outras atividades.

A Base Nacional Comum Curricular (2017), como documento normativo da Educação Básica Nacional, prevê que a criança tem o direito de se desenvolver de maneira plena, contemplando o aspecto intelectual, social e emocional. E, uma das maneiras de se garantir esse pleno desenvolvimento é por meio dos jogos e brincadeiras que vão de encontro às necessidades das crianças. Nesse sentido, destaca-se a importância de uma proposta didático-pedagógica que apresente reflexóes direcionadas ao universo infantil, definindo-se estratégias adequadas à 
aprendizagem do estudante.

Dessa maneira, considerando a relevância dos jogos e brincadeiras na aprendizagem infantil, se diz que estes são imprescindíveis para o desenvolvimento integral da criança, uma vez que por meio da ludicidade ela constrói, experimenta, aprende e demonstra toda a sua criatividade. Sobre isso, Nicoletti e Filho (2004) enfatizam que durante as propostas dos jogos e brincadeiras, a criança se constrói, experimenta, pensa, aprende a dominar a angústia, a conhecer o próprio corpo, a compor sua personalidade e é nessa hora que ela manifesta toda a sua criatividade.

Os jogos e brincadeiras "possuem um determinado sentido. Sáo elementos que desenvolvem a coordenação motora, o raciocínio, as relaçôes sociais, o envolvimento, bem como fortalecem laços coletivos" (PERANZONI; ZANETTI; NEUBAUER, 2013, p. 1). Ou seja, ao jogar e brincar as crianças atribuem às suas açôes sentidos ligados à realidade, validando suas experiências. Por isso, os jogos e brincadeiras podem ser considerados como recursos que dão a oportunidade para a criança se expressar, compartilhar ideias e objetos, a superar o seu egoísmo e solucionar os conflitos que surgem nas interaçôes.

O Referencial Curricular Nacional da Educação Infantil (RCNEI, 2009) destaca que os jogos e brincadeiras favorecem a autoestima das crianças, auxiliando-as a superar progressivamente suas aquisiçôes de forma criativa. Por consequência, os jogos e brincadeiras na prática pedagógica constituiu-se como método de ensino-aprendizagem eficiente. Levando em consideração que esse recurso revela o modo como a criança percebe sua realidade e lida com os possíveis conflitos e as diversas alternativas de interação em seu meio. Além disso, enquanto recurso pedagógico para a aprendizagem infantil, os jogos e brincadeiras são elementos fundamentais para a construção do conhecimento da criança.

Sem dúvida, os jogos e as brincadeiras são fontes inesgotáveis de interação lúdica e afetiva, uma vez que constituem-se enquanto elementos implementados que favorecem experiências, oportunizando à criança a conquista e a formação da sua identidade. Logo, são um importante recurso facilitador para o processo de ensino-aprendizagem. Assim, os elementos desse processo que são mediados por métodos lúdicos adquirem mais significados e afeto durante o desenvolvimento da criança evidenciando o contexto lúdico.

\section{Resultados}

Analisando as informaçóes levantadas durante a realização do artigo, percebeu-se que propostas lúdicas são fundamentais para a construção do conhecimento da criança. Em qualquer faixa etária, a utilização de jogos e brincadeiras estimulam o desenvolvimento psicológico, social e cognitivo do aluno. Assim, o brincar é uma ação espontânea da criança que possibilita que ela se desenvolva de maneira ampla e concreta, instigando suas percepçóes, sendo possível provocálas a ponto de gerar o interesse pelo processo de aprendizagem constante.

A inserção da ludicidade no contexto educacional é imprescindível ao desenvolvimento infantil, promovendo a apropriação do conhecimento por meio de propostas prazerosas e interativas. Além disso, a ludicidade é um recurso inigualável que se, adequadamente, explorado em sala de aula, pode proporcionar inúmeras experiências ao aluno, uma vez que por meio do brincar a criança se sente motivada a se expressar com maior liberdade e sensibilidade. É nesse 
momento prazeroso que o aluno deixa transparecer aspectos relacionados à sua personalidade, bem como, situaçôes vivenciadas dentro e fora do ambiente escolar. Isso porque as atividades lúdicas não se limitam apenas a inclusão de jogos e brincadeiras na infância, mas à ações capazes de proporcionar momentos de prazer promovendo a capacidade de socializar em ambientes dos quais a criança faz parte.

Portanto, a ludicidade constitui-se como elemento básico utilizado nas propostas educativas por meio do brincar e visam a produção do saber de maneira natural e despretensiosa, desenvolvendo habilidades, descobrindo o universo, refletindo sobre a realidade e a cultura em que se vive e explorando o universo da criatividade e imaginação. De modo geral, a incorporação do brincar na prática pedagógica visa desenvolver açôes que contribuam para as inúmeras fases da aprendizagem. Ou seja, os diversos aspectos relacionados ao desenvolvimento infantil são enfatizados por meio do lúdico.

\section{Consideraçóes finais}

As consideraçóes apresentadas sobre a influência do lúdico no desenvolvimento infantil expóe claramente a relevância dos jogos e brincadeiras no processo de construção do conhecimento da criança, sobretudo no contexto educacional, sendo possível afirmar que por meio das atividades lúdicas a criança explora suas potencialidades e habilidades relacionadas a convivência, autonomia, criatividade, e imaginação. É por meio dos jogos e brincadeiras que a criança representa, cria, usa o faz de conta para entender a realidade que a cerca e vive o momento. Por isso, a ludicidade é um ato espontâneo da criança em que ela aprende enquanto brinca.

Brincando o indivíduo pratica suas potencialidades e se desenvolve, pois há todo um desafio incluído nas situaçóes lúdicas que ocasionam o pensamento e levam as crianças a alcançarem níveis de desenvolvimento que só as açóes por incentivos essenciais conseguem. Com as propostas lúdicas os alunos passam a agir e esforçar-se sem sentir cansaço, não ficam estressados porque são livres de cobranças, avançam, ousam, descobrem, realizam com alegria, sentindo-se mais capazes, mais confiantes em si mesmos e predispostos a aprender.

Portanto, na concepção didático-pedagógica sobre os jogos e brincadeiras na educação, se diz que quando as crianças são incentivadas a vivenciar tais experiências por meio de um processo organizado, elas têm a oportunidade de desenvolver capacidades indispensáveis à sua futura atuação pessoal, profissional e social. Com isso, fica evidente que os processos educacionais podem ser positivamente afetados através da ludicidade, conduzindo o educando a ampliar suas capacidades e habilidades de aprendizagem de maneira espontânea.

\section{Referências}

ALYRIO, R. D. Métodos e técnicas de pesquisa em administração. Rio de Janeiro: Fundação CECIERJ, 2009.

\section{BOCCATO, V. R. C. Metodologia da pesquisa bibliográfica e o artigo científico como}

forma de comunicaçáo. Disponível em: <http://arquivos.cruzeirodosuleducacional.edu.br/ principal/old/revista_odontologia/pdf/setembro_dezembro_2006/metodologia_pesquisa_ 
bibliografica.pdf>. Acesso em 07, set, 2021.

BRASIL. Ministério da Educação. Referenciais Curriculares Nacionais para a Educaçáo Infantil. Brasília: MEC/SEF, 2009.

BRASIL. Ministério da Educação. Base Nacional Comum Curricular. Brasília: MEC/SEF, 2017.

COLÉGIO ERASTO GAERTNER. A importância do esporte no ambiente escolar. Disponível em: < https://www.erasto.com.br/noticias/importancia-do-esporte-no-ambienteescolar>. Acesso em 13, set, 2021.

QUEIROZ, M. M. Azevedo. Educaçáo Infantil e Ludicidade. Teresina, EUFDI, 2009. LAKATOS, E. M. Fundamentos de metodologia científica. 5. ed. São Paulo: Atlas, 2007. LUCKESI, Cipriano C. Avaliaçáo da Aprendizagem Escolar. 17º ed. São Paulo: Cortez, 2005.

MOYLES, J. R. Só brincar? O papel do brincar na Educação Infantil. Porto Alegre: Artemd, 2002.

NICOLETTI, A. A. M.; FILHO, R. R. G. Aprender brincando: A utilização dos jogos, brinquedos e brincadeiras como recurso pedagógico. Revista de Divulgação Técnico-Científica. Blumenau: ICPG, 2004.

PERANZONI, Vaneza Cauduro; ZANETTI, Adriane; NEUBAUER, Vanessa Steigleder. Os jogos, os brinquedos e as brincadeiras: recursos necessários na prática educacional cotidiana. Disponível em: <https://www.efdeportes.com/efd182/os-jogos-recursos-na-praticaeducacional.htm>. Acesso em 11, set, 2021.

PIAGET, J. A construçáo do real na criança. Trad. Álvaro Cabral. Rio de Janeiro: Zahar, 1970.

VERGARA, Sylvia Constant. Projetos e Relatórios de Pesquisa em Administraçáo. São Paulo: Atlas, 2007. 